\title{
Corporeidade, Ludicidade e Contação de História na Promoção do Pensamento Computacional na Escola
}

\author{
Rozelma Soares de França \\ Departamento de Educação \\ Universidade Federal Rural de Pernambuco \\ Recife, PE, Brasil \\ rozelma.franca@ufrpe.br
}

\author{
Patrícia Tedesco \\ Centro de Informática \\ Universidade Federal de Pernambuco \\ Recife, PE, Brasil \\ pcart@cin.ufpe.br
}

\begin{abstract}
RESUMO
Diversos desafios permeiam a implementação do pensamento computacional na escola. Um deles refere-se a estratégias e materiais didáticos que deem suporte ao seu desenvolvimento na educação básica. Embora o pensamento computacional possa ser aplicado em diferentes áreas, a maioria dos estudos se concentrou no desenvolvimento de habilidades de programação, o que pode limitar o potencial de aplicação dessa competência computacional. Ainda, relativamente poucas pesquisas exploraram a relação entre atividades plugadas e desplugadas e as experiências de aprendizagem que elas geram nos estudantes. Neste contexto, esta pesquisa propõe uma abordagem para o desenvolvimento do pensamento computacional para o Ensino Fundamental I, pautada em estratégias como cognição incorporada e contação de história, buscando a melhoria da aprendizagem dos estudantes e apoio à sua percepção quanto à aplicação da Computação na resolução de problemas do dia a dia. Com o objetivo de identificar a viabilidade da proposta, um quase-experimento, de cunho quanti e qualitativo, foi realizado com estudantes do $5^{\circ}$ ano. Para tanto, um livro-jogo foi concebido, ancorado nos pressupostos teóricos adotados, e duas formas de sua implementação foram analisadas. Uma é pautada em atividades sem o uso de tecnologias digitais - desplugada - e a outra é apoiada em atividades híbridas, ou seja, com e sem o uso dessas tecnologias. Como resultado, identificou-se que o grupo que implementou a abordagem híbrida obteve melhor desempenho de aprendizagem e evidenciou, em seus diários reflexivos, maior satisfação na realização das atividades, se comparado ao grupo desplugado.
\end{abstract}

\section{PALAVRAS-CHAVE}

Pensamento Computacional. Cognição Incorporada. Contação de História. Material Didático.

Fica permitido ao(s) autor(es) ou a terceiros a reprodução ou distribuição, em parte ou no todo, do material extraído dessa obra, de forma verbatim, adaptada ou remixada, bem como a criação ou produção a partir do conteúdo dessa obra, para fins não comerciais, desde que sejam atribuídos os devidos créditos à criação original, sob os termos da licença CC BY-NC 4.0.

EduComp'21, Abril 27-30, 2021, Jatai, Goiás, Brasil (On-line)

C2021 Copyright mantido pelo(s) autor(es). Direitos de publicação licenciados à Sociedade Brasileira de Computação (SBC).

\section{Introdução}

A Computação está se tornando onipresente na sociedade sendo observadas, nos últimos anos, diversas iniciativas de promoção do pensamento computacional, tais como o Code.org e o Programaê, na educação básica. Além disso, alguns avanços foram feitos no campo da definição de currículos para fomentar competências computacionais, tendo alguns países a Computação no currículo de suas escolas (VICARI et al., 2018).

A Sociedade Brasileira de Computação (SBC, 2019) defende que é fundamental e estratégico para o Brasil que conteúdos de Computação sejam ministrados na Educação Básica; e definiu competências e habilidades do Ensino Fundamental ao Médio para os eixos que compõem tal área, a saber: Pensamento Computacional, Mundo Digital e Cultura Digital.

Contribuição similar foi feita pelo Centro de Inovação para a Educação Brasileira (CIEB, 2018) que definiu o "Currículo de Referência em Tecnologia e Computação" para apoiar as redes de ensino em suas propostas curriculares, as quais poderão aplicar tal currículo de modo transversal ou desenvolver uma área de conhecimento específica. A proposta atende da Educação Infantil ao Ensino Fundamental e está alinhada à Base Nacional Comum Curricular (BNCC).

Sendo considerado um dos eixos da Computação, o pensamento computacional pode ser definido como a "capacidade de compreender, definir, modelar, comparar, solucionar, automatizar e analisar problemas (e soluções) de forma metódica e sistemática, através da construção de algoritmos" (SBC, 2019). Pode-se considerar que ele tem cinco características principais (SELBY; WOOLLARD, 2013; CSIZMADIA et al., 2015); abrangendo a capacidade de pensar algoritmicamente, em termos de decomposição; em generalizações, identificando e fazendo uso de padrões; em abstrações, escolhendo boas representações; e em termos de avaliação.

Embora o termo tenha se popularizado com o artigo de Wing (2006), ele foi cunhado por Papert (1980) e, nos últimos anos, diversas concepções têm surgido. Pesquisas recentes tentam organizar o espaço teórico de pensamento computacional, apontando três diferentes perspectivas: cognitiva, situada e crítica; as quais poderão influenciar a natureza das questões de pesquisa 
sobre a temática, bem como o aporte usado para ensinar e avaliar a aprendizagem (KAFAI et al., 2019).

Associado ao interesse, diversos desafios permeiam a sua implementação em sala de aula. Um deles diz respeito a estratégias de aprendizagem que podem apoiar o pensamento computacional na educação básica. Ao analisar a literatura sobre a temática, Hsu et al. (2018) identificaram o emprego cada vez mais diversificado de estratégias de aprendizagem, havendo maior recorrência de adoção da Aprendizagem Baseada em Problemas, da Aprendizagem Baseada em Projetos e da Aprendizagem Baseada em Jogos. O estudo também aponta para outras estratégicas com potencial pedagógico para a educação básica, a exemplo da Aprendizagem Incorporada e a Contação de História (storytelling), que são foco deste trabalho; tendo em vista as especificidades do público-alvo - Ensino Fundamental I.

Um outro desafio diz respeito aos materiais didáticos e suas táticas de implementação associadas. Em relação às desplugadas - sem o uso de computadores - elas têm sido empregadas em diversos países, incluindo o Brasil, promovendo o pensamento computacional mesmo em escolas carentes de recursos tecnológicos; havendo estudos que reportem melhorias no desempenho dos estudantes com o uso dessa abordagem, recomenda-a na compreensão de conceitos computacionais (BRACKMANN, 2017; RODRIGUEZ et al., 2017), como também aqueles que relatam limitado sucesso (FEASTE et al., 2011; TAUB et al., 2012). Tais resultados sugerem a necessidade de pesquisas sobre como a computação desplugada pode ser usada e em que contextos.

De forma complementar, apesar de reconhecerem o valor dessas atividades, há autores que afirmam que há algo especial no trabalho com as tecnologias que não pode ser explorado por outras atividades (VALENTE, 2016). Nesse contexto, diferentes formas de interação com a tecnologia podem ser providas, possibilitando a aprendizagem dos fundamentos da Computação. Como exemplo, pode-se citar a programação orientada ao design utilizando ferramentas como o Scratch. Em uma revisão realizada por Hsu et al. (2018), foi identificado que ferramentas desse tipo são as mais utilizadas em práticas de pensamento computacional, sendo o Scratch o mais explorado, seguido do Alice, Scratch for Second Life (S4SL), LEGO e outras. Uma limitação que se pode citar nas abordagens plugadas reside no enfoque na programação; apesar do potencial de aplicação do pensamento computacional em diferentes áreas. Nesse contexto, experiências híbridas, que empregam atividades plugadas e desplugadas têm surgido e alcançado resultados satisfatórios quanto à satisfação e aprendizagem dos estudantes (MARCU et al., 2010).

Corroborando com esses achados Vicari et al. (2018) apontam para o interesse das pesquisas em atrair estudantes para a área de Computação - sem investigar os efeitos provocados pelas estratégias e materiais usados nas experiências; e reportam também que em tais estudos há uma ênfase nos mesmos aspectos, sem apresentar uma evolução significativa para pontos principais do pensamento computacional, indo para além dos algoritmos e da programação. Estes fatos podem justificar a carência de material pedagógico para apoiar a prática de professores da educação básica.
De forma complementar, o documento "Diretrizes para ensino de Computação na Educação Básica" proposto pela SBC define habilidades de Computação para os ensinos fundamental e médio, porém não fornece materiais que deem suporte ao desenvolvimento dessas habilidades.

Diante do exposto, este artigo busca lançar luz sobre como promover o pensamento computacional no Ensino Fundamental I contribuindo para as seguintes lacunas identificadas na literatura: $i$ ) a necessidade de métodos que apoiem o desenvolvimento do pensamento computacional para/com crianças; e ii) o limitado número de materiais didáticos em português que apoiem o pensamento computacional, provendo possibilidades para além da programação.

Para tanto, propõe-se uma abordagem para o desenvolvimento do pensamento computacional, situada no contexto cultural e ancorada nas estratégias de aprendizagem Contação de História e Cognição Incorporada; e que apoia o desenvolvimento de materiais didáticos para esse contexto. Para nortear esta investigação, a seguinte pergunta foi definida: Como mediar a aprendizagem de decomposição, generalização, abstração, pensamento algorítmico $e$ avaliação no Ensino Fundamental I com vistas ao desenvolvimento do Pensamento Computacional?.

A pesquisa parte do pressuposto que combinar as estratégias de aprendizagem mencionadas pode favorecer o desenvolvimento do pensamento computacional nas crianças e que uma configuração híbrida, que empregue atividades plugadas e desplugadas, também pode trazer efeitos positivos sobre esse problema. Neste artigo, portanto, será apresentada a abordagem pedagógica proposta, e sua implementação por meio do livro-jogo sertão.bit. Ainda, são reportados e discutidos os resultados do quase-experimento feito com estudantes do $5^{\circ}$ ano do Ensino Fundamental de uma escola pública; bem como tecidas algumas contribuições do trabalho e sugestões de pesquisas futuras.

\section{Percurso Metodológico}

Esta pesquisa foi realizada em diversas etapas: i) revisão de literatura; ii) concepção da abordagem pedagógica $\operatorname{AMPLIFICA}_{((\mathrm{PC}))}$, iii) desenvolvimento de material didático e iv) avaliação. Tais fases se assemelham à Design Science Research, utilizada em pesquisas como forma de diminuir o distanciamento entre a teoria e a prática; a partir do entendimento do problema, construção e avaliação de artefatos (DRESCH et al., 2015).

Pesquisas realizadas sob o paradigma da Design Science costumam ser orientadas por mais de um método científico, de acordo com a etapa que está sendo desenvolvida e com o objetivo que se deseja alcançar. Assim, dada a necessidade de compreender os impactos da abordagem proposta sobre o desenvolvimento do pensamento computacional, métodos mistos (CRESWELL \& PLANO CLARK, 2013) foram empregados em sua avaliação. As subseções seguintes detalham cada uma das etapas.

\subsection{Revisão de Literatura}

Revisões de literatura foram realizadas visando identificar os efeitos que diferentes tipos de atividades e estratégias de 
Corporeidade, Ludicidade e Contação de História na Promoção do Pensamento Computacional na Escola

aprendizagem podem provocar sobre o desenvolvimento do pensamento computacional.

Nesse contexto, foram objeto de investigação as estratégias Contação de História e Cognição Incorporada, bem como o framework Usar-Modificar-Criar e atividades plugadas e desplugadas. Este processo de busca e seleção de estudos ocorreu de forma sistemática, sendo consideradas bases de dados nacionais e internacionais.

No contexto nacional foram considerados o Portal de Publicações da Comissão Especial de Informática na Educação (CEIE), a Revista Novas Tecnologias na Educação (RENOTE) e o Workshop sobre Educação em Computação (WEI). No contexto internacional foram consideradas as bases ACM Digital Library, Educational Resources Information Center - ERIC , IEEE Xplore, ScienceDirect e Scopus. A lista de estudos retornados foi analisada, sendo incluídos os estudos primários que explicitamente abordavam os temas de interesse desta pesquisa e que estavam disponíveis na íntegra gratuitamente. A síntese desses resultados se assemelha à revisão narrativa (ROTHER, 2007), sendo descritos e discutidos o estado da arte dos temas pesquisados, e apontadas as lacunas cobertas por esta investigação.

O detalhamento com as strings de busca usadas e os resultados obtidos pode ser consultado em França (2020). Em suma, a partir do levantamento realizado identificou-se que, apesar de alguns estudos reportarem a eficácia das abordagens plugada, desplugada e híbrida no ensino dos princípios da Ciência da Computação, as configurações que podem ser adotadas nos diferentes níveis de ensino ainda é uma questão em aberto. Nesse contexto, são requeridas pesquisas que respondam a perguntas como: quando usar a abordagem desplugada e até que ponto ela pode favorecer a aprendizagem de Computação? Quando inserir a tecnologia digital nessas experiências? Quais configurações são mais favoráveis à aprendizagem considerando os diferentes níveis de ensino: desplugada-plugada, plugada-desplugada ou outra? No contexto brasileiro essas questões são especialmente importantes, tendo em vista que poucas pesquisas buscaram responder perguntas dessa natureza.

Ao focar em frameworks como o Usar-Modificar-Criar e em estratégias de aprendizagem como Contação de História e Cognição Incorporada, há um corpo de estudos que sustenta sua aplicação em práticas de pensamento computacional na educação básica, especialmente no contexto internacional. E, corroborando com esses resultados, novas pesquisas podem buscar responder problemas como: no tocando aos níveis cognitivos das atividades, quais configurações podem promover a aprendizagem e ao mesmo tempo manter os estudantes engajados em sua solução? Como o nível de complexidade das atividades pode favorecer o trabalho docente, considerando a experiência dos alunos com os conceitos computacionais explorados? Como a contação de história pode potencializar o pensamento computacional crítico das crianças? Como a cognição incorporada pode ser explorada no ensino fundamental para a promoção do pensamento computacional? E quais suas implicações em estudantes com experiência em determinados conceitos computacionais?
EduComp’21, Abril 27-30, 2021, Jataí, Goiás, Brasil (On-line)

Muitos são os problemas que podem ser investigados. Nesta pesquisa, essas diferentes estratégias de aprendizagem são integradas, aportando em uma abordagem para promover o pensamento computacional no Ensino Fundamental, a qual é detalhada na seção 3 .

\subsection{Concepção da Abordagem Pedagógica}

À luz dos resultados obtidos com as revisões de literatura, uma abordagem pedagógica, intitulada $\operatorname{AMPLIFICA}_{((\mathrm{PC}))}$, foi concebida para apoiar o desenvolvimento do pensamento computacional no Ensino Fundamental I. Ela pode ser usada para guiar o fazer pedagógico em sala de aula, como também no processo de construção de materiais didáticos de computação para esse público.

\subsection{Desenvolvimento do Material Didático}

A fase seguinte consistiu na definição de um livro-jogo, intituladopautado nos princípios da abordagem proposta, seguido de sua validação. Para a definição do sertão.bit, foram analisadas narrativas infantis e escolhida uma que retrata a vida de um conhecido personagem do sertão: o Lampião. Esta decisão pode contribuir com o engajamento dos estudantes com as tarefas propostas, como também apoiar sua percepção quanto às possibilidades de aplicação da Computação no cotidiano.

O enredo da história escolhida foi adaptado, possibilitando abordar os pilares do pensamento computacional: decomposição, generalização, abstração, pensamento algorítmico e avaliação. De forma complementar, foram consultados livros voltados à aprendizagem de conceitos matemáticos e computacionais que propõem atividades educativas e lúdicas, explorando a cognição incorporada, ainda que em seus níveis mais baixos. Esta tarefa buscou apoiar a compreensão de como as atividades podem ser estruturadas e apresentadas aos estudantes, sendo privilegiados os formatos de livros interativos, como os pop-ups.

Em paralelo, os desafios do sertão.bit foram estruturados, sendo escolhidos, para cada um deles, nomes que trazem humor, refletem o contexto cultural e despertam a curiosidade do leitor. Ainda, buscou-se nos desafios explorar o potencial pedagógico da contação de história, como também da cognição incorporada. Nesta, diferentes níveis foram considerados, havendo desafios que requerem o uso das mãos e outras, mover o corpo inteiro para sua solução. De forma complementar e estratégica, considerando a pouca ou nenhuma experiência do público-alvo com o pensamento computacional, explorou-se desafios em diferentes níveis cognitivos, com vistas à aprendizagem de conceitos da área.

\subsection{Avaliação}

Para a avaliação, um quase-experimento (SHADISH et al., 2002) foi realizado com estudantes do $5^{\circ}$ ano do Ensino Fundamental e duas táticas de implementação do sertão.bit foram analisadas: uma sem o uso de tecnologias digitais - desplugada - e outra híbrida, suportada por atividades com e sem o uso dessas tecnologias.; estando as hipóteses alternativas apontando para melhores resultados de aprendizagem e satisfação com a implementação híbrida, que ancora a $\operatorname{AMPLIFICA}_{(\mathrm{PC})) \text {. }}$ 
Para ambos os casos, livros pop-ups foram produzidos (Figura 1), assim como seus recursos complementares, utilizando materiais de baixo custo; o que pode favorecer a sua replicação em outros contextos. Materiais com esse formato para o ensino de Computação na escola, produzidos no Brasil, não foram identificados, o que aponta para uma das inovações desta pesquisa.

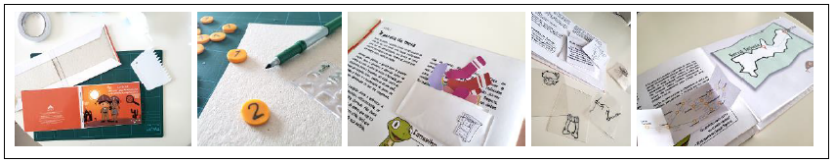

Figura 1. Processo de criação do sertão.bit

A Figura 2 exibe a configuração do quase-experimento, quanto ao tipo de atividade trabalhada e aos instrumentos de coleta de dados usados. Como mencionado, foram adotados aqueles com natureza quanti e qualitativos, a saber: pré e pós-teste, perfil, questionário Self Assessment Manikin (SAM), diário de autorreflexão, grupo focal e observação.

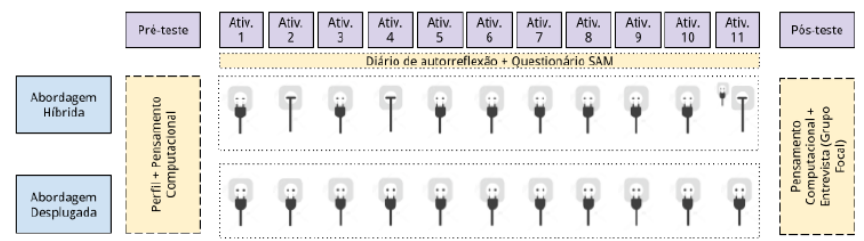

Figura 2. Configuração do quase-experimento

Visando identificar o impacto da proposta sobre o pensamento computacional, considerou-se o desempenho obtido pelos estudantes no pré e no pós-teste, os quais avaliaram os pilares Decomposição, Generalização, Abstração, Pensamento Algorítmico e Avaliação. As questões que compunham tais testes foram extraídas do Desafio Internacional de Informática e Pensamento Computacional, o Bebras (DAGIENĖ, 2006), considerando três níveis de dificuldade: fácil, intermediário e difícil. De forma complementar, as observações, o grupo focal e os relatos dos estudantes no diário de autorreflexão foram usados para elucidar os resultados.

Buscando um instrumento para avaliação do pensamento computacional adequado ao perfil desta pesquisa, é válido salientar que um estudo preliminar com estudantes do $5^{\circ}$ ano do Ensino Fundamental foi realizado com o teste proposto por RománGonzález (2016). Nesse piloto, alguns estudantes declararam não estar entendendo o que algumas questões do teste pediam; outros, demonstraram impaciência. Embora a sintaxe apresentada nos exemplos desse teste fosse usada também nas questões propostas, havia dificuldade na compreensão dos comandos. Por estes motivos decidiu-se optar por outro instrumento para avaliar o desenvolvimento do pensamento computacional no experimento, $\mathrm{o}$ Bebras.

Já em relação à avaliação da satisfação dos estudantes para com a proposta, considerou-se o resultado obtido com o questionário SAM, que avalia o estado afetivo nas dimensões satisfação, motivação e controle (Figura 3). Esse instrumento é pictográfico, o que o torna acessível para pessoas com baixa capacidade de alfabetização, incluindo crianças e idosos. A versão do SAM usada nesta pesquisa foi a proposta por Hayashi et al. (2016), que fez modificações da versão original após seu uso com crianças, tornando-o mais atrativo e fácil de entender. Adicionalmente foram considerados os relatos do diário de autorreflexão, bem como as observações feitas e as entrevistas em formato de grupo focal para responder à questão em foco.

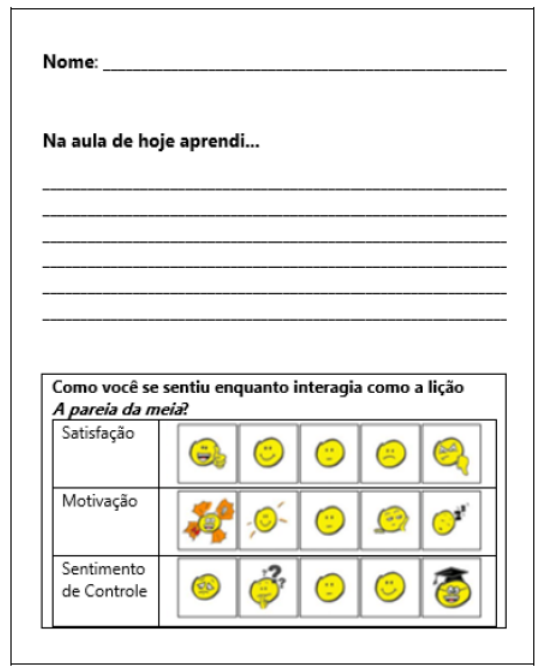

\section{Figura 3. Diário de autorreflexão e SAM}

Dada a restrição de espaço, neste artigo serão apresentados os resultados relativos ao impacto da proposta sobre o desenvolvimento do pensamento computacional. Informações adicionais podem ser consultadas em França (2020).

\section{A Abordagem AMPLIFICA $((\mathrm{PC}))$}

A AMPLIFICA $_{((\mathrm{PC}))}$ é uma abordagem pedagógica que objetiva apoiar a aprendizagem de decomposição, generalização, abstração, pensamento algorítmico e avaliação, considerados os pilares do pensamento computacional, no Ensino Fundamental I. Seu nome faz referência a possibilidades de ensino para além da programação, explorando a natureza interdisciplinar do pensamento computacional.

Sua concepção baseou-se em evidências científicas, discutidas na Seção 1, tendo como principais aportes teóricos a Cognição Incorporada (FADJO, 2012), a Contação de História (PARHAMMOCELLO et al., 2019) e o framework Usar-Modificar-Criar (LEE et al., 2011); explorando os contextos dos atores envolvidos nos processos de ensino e aprendizagem (VYGOTZKY, 1978; KAFAI et al., 2019; ORTIZ et al., 2018). Ainda, como táticas de implementação, atividades plugadas e desplugadas são providas, numa perspectiva híbrida (TSARAVA et al., 2019; MARCU et al., 2010). Uma visão geral da $\operatorname{AMPLIFICA}_{((\mathrm{PC}))}$ pode ser conferida na Figura 4.

A AMPLIFICA $((\mathrm{PC}))$ pode orientar a prática docente e também apoiar a concepção de materiais didáticos no ensino fundamental. Como pode-se observar na Figura 1, ela integra um conjunto de estratégias, que combinadas podem favorecer a aprendizagem de Computação das crianças; e a forma de implementação de cada uma delas é descrita nas subseções a seguir. 


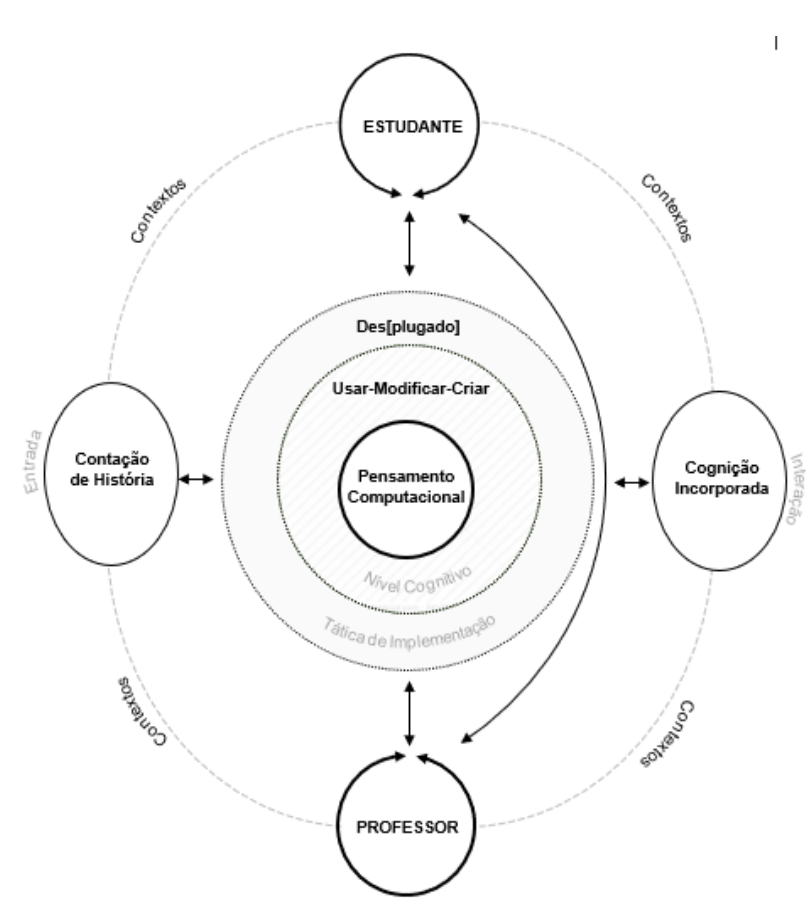

Figura 4: Visão geral da $\operatorname{AMPLIFICA}_{((\mathrm{PC}))}$

\subsection{Contação de História}

$\mathrm{O}$ ato de contar histórias é usado como estratégia para introduzir um ou mais conceitos associados ao pensamento computacional. É a porta de entrada para os gatilhos de aprendizagem que serão acionados. Com ele, pretende-se prover uma experiência crítica e engajadora de aprendizagem de Computação.

Três aspectos principais são considerados nesta dimensão. $\mathrm{O}$ primeiro deles diz respeito ao contexto sociocultural, que ainda é pouco reconhecido e considerado em pesquisas sobre pensamento computacional (ORTIZ et al., 2018). Assim, para essas histórias, propõe-se a escolha de figuras contextualmente relevantes, o que pode engajar os estudantes e promover a aprendizagem da cultura regional e de conceitos computacionais aportados na narrativa. De modo complementar, ao considerar os contextos e envolver os estudantes em desafios como os políticos, morais e éticos, o Pensamento Computacional Crítico (KAFAI et al., 2019) é explorado, apoiando a educação em Computação para a justiça social.

O segundo aspecto que apoia este eixo é pautado em ParhamMocello et al. (2019) ao afirmarem que o uso de histórias conhecidas pode fazer os alunos se sentirem mais empolgados com os problemas; e que ao identificar conceitos computacionais em histórias e situações cotidianas a relevância da área pode ser enfatizada. Também, a aprendizagem pode ser facilitada, uma vez que os estudantes precisam entender apenas o vínculo entre os elementos da história e os conceitos de Computação. Por fim, no terceiro aspecto sugere-se que a história seja contada a partir de recursos além do texto. Variadas mídias podem compor essa experiência, como jogos físicos e digitais, que podem ser produzidos explorando o potencial das narrativas transmídias (JENKINS, 2007).

\subsection{Cognição Incorporada}

Buscando uma experiência de aprendizagem mais concreta a conceitos abstratos, sugere-se pautar as atividades do Ensino Fundamental I na Cognição Incorporada; demonstrando como processos complexos subjacentes ao pensamento computacional emergem de práticas concretas, situadas e baseadas na ação do estudante no ambiente (FADJO, 2012). As atividades podem contemplar diferentes níveis de incorporação, perpassando três fatores: envolvimento sensório-motor, congruência gestual e sensação de imersão (JOHNSON-GLENBERG et al., 2016).

Artefatos tangíveis/manipulativos e recursos de realidade aumentada podem apoiar a implementação dessa estratégia e o estudante poderá usar as mãos, por exemplo, ou o corpo inteiro para a resolução das tarefas. Embora atividades com lápis, caneta e papel sejam as mais citadas em práticas de pensamento computacional desplugado (RODRIGUES et al., 2018); sugere-se que outros tipos de recursos sejam explorados, como jogos de tabuleiro; possibilitando uma interação estudante-material em um nível mais alto de incorporação. Para aqueles estudantes com pouca ou nenhuma experiência nos conceitos computacionais trabalhados, esse nível de incorporação mais elevado pode possibilitar uma experiência de aprendizagem mais imersiva e relevante por meio da manipulação desses artefatos.

\subsection{Usar-Modificar-Criar}

Buscando favorecer a compreensão de conceitos computacionais, como também envolver os estudantes nas atividades em níveis de engajamento cada vez mais profundos, propõe-se o uso da progressão Usar-Modificar-Criar (LEE et al., 2011) para estruturação das atividades de pensamento computacional. A partir de tal framework, o estudante poderá avançar de usuário até criador de artefatos computacionais, não necessariamente de forma linear. Atividades que envolvem modificação, por exemplo, podem ser intencionalmente planejadas para que o estudante tente abstrair partes irrelevantes do código e foque em estruturas computacionais que se deseja que ele aprenda naquela etapa.

Ainda, pode-se planejar configurações mais favoráveis aos processos de ensino e aprendizagem com a etapa de criação. Considerando uma turma sem experiência em pensamento computacional, por exemplo, iniciar as atividades no nível Criar pode dificultar o fazer pedagógico, especialmente se os projetos forem de acordo com as preferências dos estudantes; uma vez que irá requerer mais tempo para um atendimento personalizado encoraja-se a personalização, contudo, pontua-se sobre suas possíveis dificuldades de implantação nesta etapa. Ainda, ao iniciar as atividades propondo um nível superior ao já desenvolvido pelos estudantes, pode provocar desmotivação logo no início dessa etapa de aprendizagem. Portanto, o equilíbrio deve ser buscado, não fornecendo atividades fáceis ou difíceis em demasia. 


\section{4. [Des]plugado}

Propõe-se um formato híbrido como tática de implementação das atividades de pensamento computacional no Ensino Fundamental I. Isto, porque, embora estudos reportem resultados positivos com o uso de táticas plugadas e desplugadas, separadamente (GARDELI; VOSINAKIS, 2018); há algo especial no trabalho com as tecnologias que não pode ser explorado por outras atividades (VALENTE, 2016). Isto deve ser levado em consideração especialmente por a satisfação ser um dos fatores-chave de aprendizagem. Desse modo, pode-se, por exemplo, em um primeiro momento propor atividades sem o uso do computador para que o estudante se familiarize com os conceitos fundamentais da Computação, formulando e testando seus algoritmos. Nesse momento ele poderá analisar o problema e concentrar-se no procedimento passo a passo para sua solução, sem se preocupar com quaisquer regras de sintaxe. Com isso, o estudante poderá pensar no que está fazendo, ao invés de tentar resolver somente no modo de tentativa e erro.

Em outro momento, atividades híbridas podem ser propostas, podendo haver um enfoque na modificação, como estratégia para apreensão de habilidades específicas. De forma complementar, o estudante poderá formular e testar seus algoritmos, convertendo-os em código executável em ambientes de programação visual e observar sua execução, assim como refinar sua solução. Também, sob uma perspectiva vygotskiana, considerando a importância do brincar; as atividades podem explorar a ludicidade própria do público-alvo em questão; o que poderá repercutir sobre suas aprendizagens.

Para além do formato, essas atividades podem explorar a natureza interdisciplinar do pensamento computacional, promovendo a aprendizagem de Computação e de outras disciplinas do currículo escolar. A Contação de História, pontuada anteriormente, poderá nortear essa prática, direcionando os caminhos que serão explorados. Em uma narrativa que retrata a vida no sertão, por exemplo, elementos como literatura e música popular podem ampliar o repertório do pensamento computacional para além da programação.

\subsection{Atores e Contextos}

As interações sociais (VYGOTZKY, 1978) desempenham papel fundamental no desenvolvimento do pensamento computacional. Assim, as atividades aparecem como instrumento e sua ação é melhor consolidada com a mediação dos pares. Nesse sentido, o professor é figura fundamental, o qual deve contar com sugestões de atividades que poderão nortear o seu fazer pedagógico; e também dialogar com professores de outras áreas para elaboração e/ou implantação dessas atividades. Também, scaffolds podem ser planejados como forma de ajudar o estudante na resolução dos problemas. Ao se adotar uma abordagem híbrida, tais elementos merecem uma atenção especial. Isto porque em atividades plugadas o feedback em atividades avaliativas, por exemplo, poderá ser imediato, enquanto que nas ditas desplugadas, esse retorno pode ser mais demorado. Considera-se importante também o diálogo entre os estudantes, construindo aprendizagens de forma colaborativa. A interlocução com seus contextos pode ser materializada na história contada, como também no entendimento e construção de soluções para os problemas propostos.

\section{Implementando a Abordagem Proposta}

Como forma de avaliar o potencial da AMPLIFICA $_{((\mathrm{PC}))}$ um livrojogo, intitulado sertão.bit, foi concebido; instanciando os elementos dessa abordagem e tendo como público-alvo o Ensino Fundamental I. Sua proposta inicial foi apresentada em França \& Tedesco (2019) e, neste trabalho, apresenta-se sua versão refinada.

\subsection{Concepção do sertão.bit}

O sertão.bit objetiva apoiar a aprendizagem dos pilares do pensamento computacional. Para tanto, explora o contexto cultural a partir de uma narrativa infantil sobre Lampião no sertão de Pernambuco como forma de engajar os estudantes durante a aprendizagem e possibilitar identificar aplicações dos conceitos computacionais explorados em situações do dia a dia.

Ancorado na abordagem $\operatorname{AMPLIFICA}_{((\mathrm{PC}))}$, buscou-se na literatura histórias que retratassem personagens conhecidos da região, tais como Luiz Gonzaga e Lampião. Dado seu enredo, "A história de Lampião Júnior e Maria Bonitinha” de Alves (2009) foi escolhida para pautar o sertão.bit. Na obra, a autora utiliza-se da licença poética que textos infantis possibilitam e narra a história de Lampião, em sua infância. O texto faz referência a diferentes situações nas quais Lampião Júnior e sua turma se envolvem em busca de uma solução para o sertão pernambucano sobreviver à profecia de virar mar.

Em sertão.bit, tal profecia embasa as lições e o leitor deve ajudar Lampião Júnior e sua turma a terem sucesso nessa jornada. Alguns episódios foram adaptados da história original e outros, criados, possibilitando o trabalho com os pilares do pensamento computacional. Os desafios propostos vão além da programação. Algoritmos embasam alguns deles, mas os demais pilares do pensamento computacional também são explorados. Além disso, boa parte dos exemplos do livro pode ser aplicada na resolução de problemas do dia a dia, tais como encontrar o par de uma meia em um amontoado de meias; localizar uma sala mais rapidamente, em um conjunto de dezenas de salas; identificar a melhor rota em um trajeto, dentre outros. De forma complementar, o material possibilita identificar elementos do folclore, dança e música nacionais.

Em relação ao formato, optou-se por um livro-jogo pop-up, tendo em vista a importância do brincar para o Ensino Fundamental I, reportada na AMPLIFICA $((\mathrm{PC}))$. Um dos livros-jogo usado como referência foi o "The Incredible Math Games Book" (DK Publishing, 2015) que introduz conceitos básicos matemáticos. No contexto da Computação, o "Hello Ruby" (LIUKAS, 2015), o "My First Coding Book" (PROTTSMAN, 2017) e o "Brincar e aprender: Computadores e programação" (USBORNE, 2015) foram analisados. Esses materiais inspiraram a forma de apresentação dos desafios propostos no sertão.bit, especialmente aqueles dos níveis mais baixos da Cognição Incorporada, em que o estudante usa as mãos para interagir com o material e aprender. 
Pautado na Cognição Incorporada, as atividades do sertão.bit exploram diferentes níveis de incorporação. O livro per si possui formato físico e alguns materiais complementares o acompanham, podendo promover uma experiência de aprendizagem mais engajadora, se comparado a livros correlatos dispostos na literatura (KUBICA, 2012; LIUKAS, 2015; BUENO, 2016). Atividades como "A pareia da meia" e "Criaturas do mato" podem ser consideradas no segundo nível de incorporação da taxonomia proposta por Johnson-Glenberg et al. (2016). Isto porque elas dispõem de manipulativos para o estudante interagir com as mãos e resolver e testar suas soluções. A "Disputa do xaxado", por outro lado, pode ser enquadrada no quarto nível, o mais alto de incorporação, envolvendo o corpo do estudante na interação com um dos jogos implementados. Para tal, com os pés sobre um tapete, ele simula os passos do xaxado ${ }^{1}$ a partir de uma sequência apresentada e observa na tela os resultados da sua ação com os pés.

Em relação à estruturação das atividades, a progressão UsarModificar-Criar (LEE et al., 2011) sugerida pela AMPLIFICA $((\mathrm{PC}))$ foi usada. Na atividade "Trio Desafinado", por exemplo, é solicitado que o estudante corrija um erro em uma parte do código. Este erro foi intencionalmente planejado para que o estudante tente abstrair partes irrelevantes do código e foque em estruturas de repetição, conteúdo este que se deseja que ele aprenda nesta etapa do sertão.bit.

O livro-jogo proposto tem um formato híbrido, explorando táticas plugadas e desplugadas para implementação das atividades. Boa parte das atividades desplugadas propostas é voltada para a apreensão de conceitos computacionais; enquanto que a tecnologia digital provê novas e distintas experiências com esses conteúdos. Indo além do texto, a história é contada também a partir de jogos físicos e digitais implementados no Scratch, explorando assim o potencial das narrativas transmídias e se diferenciando de livros já citados; que se propõem a promover o pensamento computacional para crianças.

Como reportado, no sertão.bit são propostas atividades que perpassam do uso à criação. Nesta etapa, é proposto ao estudante formular e testar algoritmos, convertendo-os em código executável no Scratch. Antes, contudo, ele se envolve no processo de criação de uma xilogravura ${ }^{2}$ que será usada como cenário para seu projeto. Na proposta, ela aparece como expressão criativa do estudante, podendo tornar o projeto mais significativo para ele, que também tomou a decisão de qual ação programar, dentre as sugeridas para o final da narrativa.

No que diz respeito à escolha do ambiente para apoiar as atividades plugadas do livro, a decisão pelo Scratch foi baseada em revisões sistemáticas de literatura que identificaram que ambientes com suas características são os mais empregados em práticas de pensamento computacional na educação básica (YU; ROQUE, 2019). Por fim, as interações sociais são propiciadas nas atividades propostas no sertão.bit, seja na relação professor-aluno, como também aluno-aluno. De modo complementar, scaffolds foram

\footnotetext{
${ }^{1}$ Xaxado é uma dança popular brasileira originada no Sertão de Pernambuco.
}

planejados como forma de ajudar o estudante na resolução dos desafios. Tal elemento aparece representado no livro por meio de uma lagartixa (Figura 5) que faz referência a Alan Turing, o pai da Ciência da Computação. Na apresentação do livro é sugerido que, em caso de dúvida, o leitor recorra a esse apoio, acessando a seção chamada "Conselho de Turing" de cada desafio.

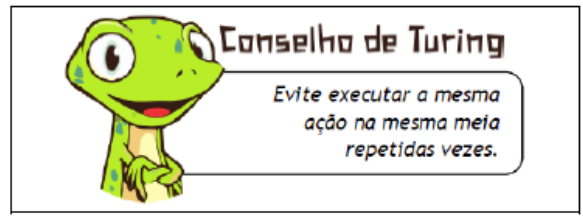

\section{Figura 5. Exemplo de Conselho de Turing}

\subsection{Estrutura do livro-jogo}

O sertão.bit começa apresentando um diálogo entre Lampião Júnior e seu avô em um dia chuvoso no sertão pernambucano. Se por um lado aquela chuva trazia gotas de esperança à seca que assolava a região, por outro remetia à profecia de Padim Ciço do Juazeiro que disse que, um dia, o sertão iria virar mar. Entre uma conversa e outra e sob a benção de seu avô e proteção de seus santos de devoção, Lampião Júnior decide partir em busca de cumprir sua promessa: evitar que o sertão vire mar. É neste momento que iniciam os desafios do livro-jogo e o estudante deve ajudar Lampião Júnior a cumpri-los da maneira mais eficiente. O Quadro 1 apresenta a sumarização dos desafios, destacando seu tipo (desplugado ou plugado) e componentes de pensamento computacional explorados.

\begin{tabular}{|c|c|c|c|c|c|c|}
\hline \multirow[b]{2}{*}{ Desafio } & \multirow[b]{2}{*}{ Tipo } & \multicolumn{5}{|c|}{ Componentes Pensamento Computacional } \\
\hline & & Decomposição & Generalização & Abstração & $\begin{array}{l}\text { Pensamento } \\
\text { Algorítmico }\end{array}$ & Avaliação \\
\hline A pareia da meia & i & $x$ & $\mathrm{x}$ & $x$ & $\mathrm{x}$ & $\mathrm{x}$ \\
\hline Trio desafinado & $\mathrm{T}$ & $\mathrm{x}$ & $\mathrm{x}$ & $\mathrm{x}$ & $\mathrm{x}$ & $\mathrm{x}$ \\
\hline $\begin{array}{l}\text { Um poema para } \\
\text { Maria Bonitinha }\end{array}$ & i & $x$ & $\mathrm{x}$ & $\mathrm{x}$ & & \\
\hline Disputa do xaxado & $\mathrm{T}$ & & $\mathrm{x}$ & $\mathrm{x}$ & $\mathrm{x}$ & \\
\hline $\begin{array}{l}\text { Mandacaru } \\
\text { matemático }\end{array}$ & i & $x$ & $x$ & $x$ & & $x$ \\
\hline Criaturas do mato & , & $\mathrm{x}$ & $\mathrm{x}$ & $\mathrm{x}$ & $\mathrm{x}$ & $\mathrm{x}$ \\
\hline Rota do cangaço & , & $\mathrm{x}$ & & $\mathrm{x}$ & $\mathrm{x}$ & $x$ \\
\hline $\begin{array}{l}\text { Repartir para } \\
\text { achar }\end{array}$ & i & $\mathrm{x}$ & $\mathrm{x}$ & $x$ & & \\
\hline $\begin{array}{l}\text { O labirinto de } \\
\text { Lampiäozinho }\end{array}$ & i & & & $\mathrm{x}$ & $\mathrm{x}$ & $\mathrm{x}$ \\
\hline $\begin{array}{l}\begin{array}{l}\text { Salvo pelo } \\
\text { algoritmo }\end{array} \\
\end{array}$ & i & & & $\mathrm{x}$ & $\mathrm{x}$ & $\mathrm{x}$ \\
\hline Eu autor & - T & $\mathrm{x}$ & $\mathrm{x}$ & $\mathrm{x}$ & $\mathrm{x}$ & $\mathrm{x}$ \\
\hline
\end{tabular}

\section{Quadro 1: Visão geral dos desafios do sertão.bit}

A título de ilustração, pode-se citar o desafio "Disputa do xaxado" que simula um duelo entre dois personagens na história: Lampião Júnior e Corisquinho, amigo de Maria Bonitinha. Nessa disputa, quem dançar melhor xaxado, ganha. Esta atividade integra recursos físicos e digitais: foi construído um tapete (Figura 6B), como material complementar do livro-jogo, para que o leitor interaja com um projeto Scratch por meio de um kit que transforma

${ }^{2}$ Xilogravura consiste na arte e técnica de fazer gravuras em relevo sobre madeira. Neste trabalho, é proposto que os estudantes executem a tarefa em isopor ou E.V.A. A imagem resultante dessa tarefa é usada como plano de fundo de seus projetos Scratch. 
objetos cotidianos em interfaces touch pads, tais como o MakeyMakey e o FRANZMakey. A disputa é feita entre dois estudantes: um representa o Lampião Júnior e o outro, o Corisquinho. Cada um deve memorizar a sequência de passos que simula o xaxado, apresentada na tela do computador, e reproduzila, movendo seus pés sobre o tapete. Essa proposta é baseada no jogo Genius que estimula a memorização de cores e sons. À medida em que vai interagindo e reproduzindo os passos corretamente, vai pontuando. Ganha quem concluir mais níveis.

Neste desafio, os estudantes podem ser identificados por chapéus, representando cada um dos personagens (Figura 6A). Para interagir com o projeto Scratch criado, foi construído um tapete de baixo custo, com papelão e coberto por papel alumínio que serve como um condutor. A integração do jogo Scratch ao tapete está demonstrada na imagem com o FRANZMakey.

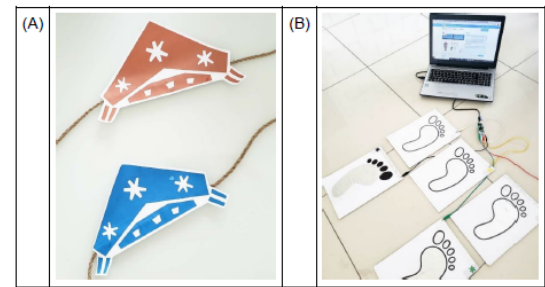

Figura 6. Disputa do xaxado - Manipulativos. A) chapéu; B) tapete

Um outro desafio do sertão.bit é o "Mandacaru matemático". Dentre os personagens da história tem-se Cacne, um mandacaru. E é a partir dele que esse desafio foi construído. É proposto que o leitor observe a imagem de Cacne (Figura 7A) e tente identificar algum padrão em sua forma. Após ser apresentado ao conceito e exemplo de fractal, é proposto também que ele identifique a parte que está se repetindo em outra imagem e que use essa parte, desenhando-a quantas vezes forem necessárias até chegar no resultado demonstrado na Figura 7B.

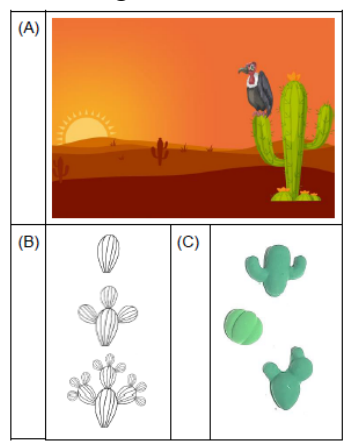

Figura 7. Mandacaru matemático. A) ilustração; B) solução; C) manipulativos

Caso os estudantes tenham dificuldade de abstrair os elementos do desenho original e focar essencialmente no formato de Cacne, sugere-se o uso dos manipulativos do livro (Figura 4C), demonstrando outros formatos de cacto e solicitando também a identificação das partes que se repetem. Feito isso, dar-se seguimento com a atividade proposta com o personagem Cacne.

O livro-jogo e seus recursos associados podem ser acessados na íntegra no site $<$ www.falecomrozelma.com $>$.

\section{Vivências e Diálogos na Escola}

Para avaliar o impacto da $\mathrm{AMPLIFICA}_{((\mathrm{PC}))}$ sobre o pensamento computacional, um quase-experimento foi realizado com estudantes do $5^{\circ}$ ano do ensino fundamental, com o uso de métodos mistos.

Esse quase-experimento foi realizado como uma oficina de Pensamento Computacional em uma Unidade de Tecnologia (UTEC) de Pernambuco, que atende escolas municipais de seu entorno. Neste artigo, foi feito um recorte dos dados buscando-se responder à seguinte pergunta:

- Houve melhoria no desempenho em pensamento computacional?

Para respondê-la, considerou-se o desempenho obtido pelos estudantes no pré e no pós-teste já mencionado na Seção 2. Em relação às hipóteses, as seguintes foram definidas para nortear este quase-experimento:

- Hipótese Nula (H0): O desempenho médio dos estudantes que utilizaram a abordagem $\operatorname{AMPLIFICA}_{((\mathrm{PC}))}$ suportada por atividades híbridas é igual ao obtido por aqueles que estudaram com tal abordagem apoiada por atividades desplugadas.

- Hipótese Alternativa (H1): O desempenho médio dos estudantes que utilizaram a abordagem $\operatorname{AMPLIFICA}_{((\mathrm{PC}))}$ suportada por atividades híbridas é melhor do que o obtido por aqueles que estudaram com tal abordagem apoiada por atividades desplugadas.

O quase-experimento contou com a participação de 48 estudantes, distribuídos igualmente entre dois grupos. A turma da manhã foi chamada de "grupo experimental" e, nela, foram implementadas as atividades híbridas. Já na turma da tarde, chamada de "grupo controle", as atividades seguiram o formato desplugado.

\subsection{Perfil dos Participantes}

Embora 24 estudantes integrassem cada turma, 19 e 18 participaram de algum momento do quase-experimento e realizaram o pré e o pós-teste nos grupos controle e experimental, respectivamente. Assim, os dados reportados dizem respeito a essa amostra da população.

Em relação à idade, em ambos os grupos variava entre 10 e 12 anos, exceto um do grupo controle que tinha 14 anos. Nenhum deles reportou experiência prévia com cursos sobre pensamento computacional.

\subsection{Pensamento Computacional}

Com vistas a identificar o impacto da abordagem proposta sobre o pensamento computacional, o pré e o pós-teste foi analisado. Nove questões integraram cada teste, sendo três de cada nível de dificuldade: fácil, intermediário e difícil. Às questões do nível fácil, foi atribuído peso três. Às dos níveis intermediário e difícil, pesos 9 e 12, respectivamente. Assim, a nota máxima que os estudantes poderiam obter em cada teste era 81 .

A Tabela 1 apresenta as médias obtidas pelos participantes deste estudo em sua avaliação da aprendizagem. Como pode ser 
Corporeidade, Ludicidade e Contação de História na Promoção do Pensamento Computacional na Escola

observado, o grupo experimental apresentava inicialmente uma média ligeiramente menor que o grupo controle. Após as intervenções didáticas com o sertão.bit, ambos os grupos tiveram aumento de desempenho de pensamento computacional. Contudo, o grupo experimental demonstrou um ganho mais expressivo, se comparado ao controle.

\begin{tabular}{|c|c|c|c|c|}
\hline \multirow{2}{*}{ GRUPOS } & \multicolumn{2}{|c|}{ PRÉ-TESTE } & \multicolumn{2}{|c|}{ PÓS-TESTE } \\
\hline & Média & Desvio Padrão & Média & Desvio Padrão \\
\hline Grupo Experimental & 34,8 & 15,31 & 53,7 & 18,08 \\
\hline Grupo Controle & 35,72 & 17,15 & 41,45 & 15,28 \\
\hline
\end{tabular}

Tabela 1. Resultado do desempenho em pensamento computacional

Objetivando-se averiguar a significância estatística dos resultados apresentados, verificou-se inicialmente se os grupos são equivalentes usando o teste de Shapiro-Wilk (SHAPIRO; FRANCIA, 1972). Os resultados apontam para uma distribuição normal. Desse modo, um teste $t$ de Student (ALVES, 2017) foi usado para analisar as hipóteses H0 e H1. A hipótese nula afirma que os resultados obtidos pelo grupo experimental são iguais aos do grupo controle no que diz respeito ao desempenho em pensamento computacional. Todavia, a hipótese alternativa declara que tais resultados são diferentes.

Tendo em vista as médias obtidas pelos estudantes no pós-teste, com o auxílio do MS Excel utilizou-se o teste $\mathrm{t}$ sobre as duas amostras com nível de significância de 5\%. O valor-P resultante foi aproximadamente 0,0423. Desse modo, considerando que ele é inferior a 5\%, a hipótese nula é rejeitada e há aceitação da hipótese alternativa. Isto implica dizer que existe relação entre a abordagem híbrida com o uso do sertão.bit e a aprendizagem de técnicas de pensamento computacional.

Ao analisar os diários de autorreflexão dos estudantes, focando nos dados daquelas atividades que foram desplugadas, percebe-se que a "Trio desafinado", obteve em sua totalidade no grupo experimental, comentários relacionados à apreensão de conceitos computacionais. No grupo controle, embora a maioria deles ser voltado a esses conceitos, alguns estudantes fizeram comentários associadas à satisfação na realização da tarefa, demonstrando o potencial pedagógico de ambas as propostas. Essas duas categorias de respostas (aprendizagem de conceitos computacionais e satisfação) emergiram dos dados a partir de sua análise de conteúdo (MORAES, 1999).

$\mathrm{Na}$ "Disputa do xaxado", o grupo experimental teceu em maior recorrência comentários associados à satisfação; enquanto que o grupo controle, à aprendizagem de conceitos computacionais. Esses dados dão suporte à modificação das configurações desse desafio, contemplando as duas abordagens conjuntamente.

$\mathrm{Na}$ "Eu autor", tanto aspectos de satisfação quanto de aprendizagem são registrados nos comentários do grupo experimental; embora os primeiros apareçam com mais frequência. O grupo controle, por outro lado, teceu em sua totalidade comentários associados a conceitos computacionais. Esse resultado apoia estudos que defendem a adoção da abordagem desplugada para introduzir conceitos; como também aqueles que veem nas
EduComp’21, Abril 27-30, 2021, Jataí, Goiás, Brasil (On-line)

tecnologias características que as tornam especiais no contexto educacional.

\subsection{Caminhos para o Pensamento Computacional Situado e Crítico}

A partir das entrevistas com os dois grupos focais, ao final do quase-experimento, tentou-se identificar elementos que dessem suporte aos achados reportados. Quanto às características do livro, os alunos teceram comentários sobre Lampião, evidenciando duas características principais: corajoso e aventureiro; embora poucos conhecessem uma versão de sua história antes do estudo realizado. A proposta do sertão.bit, para além do pensamento computacional, apoiou, pelo menos, o interesse dos estudantes em buscar e se aprofundar em mais elementos da cultura regional. Houve relatos, por exemplo, de estudantes que não conheciam o xaxado ou outras danças da região; e também aqueles que reportaram já ter visto, mas sem um olhar mais atento, e que demonstraram interesse pelos elementos após o trabalho realizado.

Outro dado que chama a atenção é o relato de dois alunos, sendo um de cada turma, que demonstraram estranheza quanto ao desafio "A pareia da meia". Ao serem questionados sobre o que mudariam no sertão.bit, esse desafio foi por eles citado. À primeira vista a impressão tida foi que eles não tinham conseguido resolvê-lo, mas ao continuar com a entrevista ficou claro que a reação contrária foi pela presença de meias naquele cenário: "quem é do sertão que usa meia?... como que eles iriam comprar meia?...”. Aqui o Pensamento Computacional Crítico se releva e, falas como essas, podem ser um gatilho para discussões sobre desafios estruturais da sociedade, podendo também ser explorados pela produção de mídias digitais.

Também, nas entrevistas buscou-se ouvir deles sobre aspectos associados à colaboração na resolução dos desafios; que intrinsicamente se relacionam com uma perspectiva situada de aprendizagem. Quando questionados se conseguiriam resolver todos sozinhos, eles informam que não e apontaram o que mais tiveram dificuldade: "Repartir para achar". De fato, este desafio tem um nível de dificuldade mais elevado se comparada aos demais, e na versão atual talvez seja mais adequada para um público-alvo um pouco mais velho. Por outro lado, o livro como um todo foi bem aceito pelo $5^{\circ}$ ano, havendo comentários como "Eu nunca vi igual", e a "Disputa do xaxado" estando na preferência desse público.

\subsection{Implicações para a Pesquisa}

A partir dos resultados reportados e discutidos, propõe-se algumas mudanças nas configurações dos desafios do sertão.bit, pautadas também pelos aspectos teóricos que sustentam a abordagem proposta:

- $\quad$ A pareia da meia: os manipulativos propostos atingiram seu objetivo. Sugere-se, contudo, que dependendo do ano escolar este desafio seja feito em dupla, pois alguns estudantes reportaram somente o método mais óbvio para combinação dos pares de meia (combinar por cor e tamanho), tendo dificuldade de pensar nos conceitos mais fundamentais do problema proposto; 
- Trio desafinado: em caso de novatos, antes de se explorar o projeto do Scratch, sugere-se que os estudantes simulem sua execução usando artefatos físicos. À medida em que for aprendendo os conceitos computacionais, usar o corpo todo (alto nível de incorporação) pode não ser mais tão necessário quanto antes;

- Um poema para Maria Bonitinha: atendeu aos objetivos;

- Disputa do xaxado: dois aspectos ficaram evidentes com seu uso: aprendizagem e satisfação dos alunos. Para uma melhor experiência em ambas as dimensões, sugere-se iniciar com o formato tecnológico e em um segundo momento abordar os aspectos subjacentes ao projeto com atividades desplugadas. Essas sugestões são indicadas especialmente para os estudantes sem prévio conhecimento na área;

- Mandacaru matemático: atendeu aos objetivos;

- Criaturas do mato: atendeu aos objetivos;

- Rota do cangaço: embora o desafio esteja com uma boa configuração, alguns estudantes tiveram dificuldade de resolvê-lo. Assim, compartilhar o problema com o par pode ser uma boa estratégia;

- Repartir para achar: foi considerada o desafio mais complexo. Sugere-se seu uso em turmas mais avançadas;

- O labirinto de Lampiãozinho: embora tenha sido bem avaliada pelos alunos, sugere-se explorar níveis mais altos de incorporação nesse desafio, criando cenários de labirinto no chão, por exemplo, para que o estudante siga as trajetórias e avalie sua efetividade com o próprio corpo;

- Salvo pelo algoritmo: atendeu aos objetivos;

- Eu autor: devido a restrições de tempo no calendário escolar, não foi possível validá-lo em sua plenitude. Contudo, mesmo limitando as possibilidades de abertura para criação de artefatos pelos estudantes, obteve-se resultados satisfatórios.

Os resultados obtidos, especialmente a partir de entrevista com uma professora da UTEC que acompanhou o quase-experimento, ainda reforçam a ideia de dispor os materiais para acesso ao público, possibilitando expandir as práticas vivenciadas em novos cenários. Nesse sentido, o site <www.falecomrozelma.com $>$ foi criado e, nele, foi disponibilizado um box contendo o sertão.bit e seus desafios associados, os materiais complementares, como também sugestões para sua implementação em sala de aula.

\section{Considerações Finais}

Neste trabalho buscou-se responder à seguinte pergunta de pesquisa: Como mediar a aprendizagem de decomposição, generalização, abstração, pensamento algoritmico e avaliação no Ensino Fundamental I com vistas ao desenvolvimento do Pensamento Computacional?. Para tanto, foi proposta a abordagem pedagógica AMPLIFICA $((\mathrm{PC}))$ instanciada pelo livro-jogo sertão.bit, que pode contribuir para dois grandes problemas apontados na literatura: métodos e materiais didáticos, especialmente em português, que promovam o pensamento computacional para além da programação. Alinhados aos objetivos, em suma, pode-se citar as seguintes contribuições:

- Uma abordagem para promoção do Pensamento Computacional para/com crianças que se apoia na cognição incorporada para estender as possibilidades de aprendizagem, ao considerar que ela surge não apenas da mente, mas também por meio das interações físicas e sociais de nossos corpos com o mundo ao nosso redor. A proposta ainda é suportada pela estratégia de contação de histórias, explora diferentes níveis de engajamento das atividades (do uso à criação), considera o contexto cultural como palco para as aprendizagens e sua implementação é pautada em atividades com e sem o uso de tecnologias digitais;

- Um livro-jogo que implementa a abordagem proposta e explora uma narrativa infantil sob diferentes mídias, podendo tornar a experiência de aprendizagem de computação mais envolvente para crianças. Associada à abordagem, a criação de materiais didáticos é especialmente relevante para as comunidades de Informática na Educação e Educação em Computação no Brasil, por fornecer apoio às práticas de pensamento computacional na escola, possibilitando avançar com a pesquisa e o ensino no país;

- Análise da abordagem proposta, por meio de um quaseexperimento com estudantes do $5^{\circ}$ ano do Ensino Fundamental; sendo sugerido que sua implementação ocorra por meio de atividades híbridas. Destaca-se, no entanto, que este resultado não inviabiliza a implantação das atividades propostas em escolas carentes de recursos tecnológicos, uma vez que boa parte delas pode ser realizada sem esses recursos e os resultados obtidos, em seu formato desplugado, demonstram satisfação no uso pelos estudantes, como também traz impactos positivos sobre seu desempenho de aprendizagem.

Com vistas a apoiar a validade dos resultados, métodos quanti e qualitativo foram empregados, buscando entender com maior profundidade a emergência do pensamento computacional a partir das práticas com o sertão.bit. Questões que podem influenciar o resultado dizem respeito à seleção e à amostra dos estudantes que participaram do quase-experimento. Desse modo, em trabalhos futuros almeja-se replicá-lo em outros anos escolares, envolvendo um número maior de participantes e iterações; e também analisar como a narrativa empregada no sertão.bit pode favorecer a aprendizagem de estudantes distantes do contexto cultural explorado. Ainda, um ponto relevante que urge dos resultados diz respeito ao Pensamento Computacional Crítico, pelo qual a Educação em Computação pode caminhar, alinhada à pedagogia crítica, com vistas à justiça social no país.

\section{AGRADECIMENTOS}

A Paulo Ricardo Silva. pela ilustração do sertão.bit e à escola por todo o envolvimento na realização do quase-experimento.

\section{REFERÊNCIAS}


Corporeidade, Ludicidade e Contação de História na Promoção do Pensamento Computacional na Escola

[1] Alves, Januária Cristina. A história de Lampião Júnior e Maria Bonitinha. Bonobo Kids, 2009.

[2] Alves, Marcelo Correa. Teste $\mathrm{t}$ de Student. 2017. Disponível em < http://cmq.esalq.usp.br/wiki/lib/exe/fetch.php?media=publico:syllabvs:lcf5759a :teste_t.pdf $>$. Acesso em 15 de outubro de 2019.

[3] Brackmann, C. P. Desenvolvimento do Pensamento Computacional através de atividades desplugadas na Educação Básica. 2017. Tese de Doutorado.

[4] Bueno, Carlos. Lauren Ipsum: uma história sobre Ciência da Computação e outras coisas importantes. Novatec, 2016.

[5] CIEB - Centro de Inovação para a Educação Brasileira. Currículo de Referência em Tecnologia e Computação: Da Educação Infantil ao Ensino Fundamental. 2018. Disponível em <http://curriculo.cieb.net.br/>. Acesso em: 23 jan. 2020.

[6] Creswell, J. W.; Plano Clark, V. L. Pesquisa de métodos mistos. 2.ed. Porto Alegre: Penso, 2013.

[7] Csizmadia, A., Curzon, P., Dorling M., Humphreys, S., Ng, T., Selby, C., Woollard, J. 2015. Computational thinking-A guide for teachers. Disponível em $<$ https://community.computingatschool.org.uk/resources/2324/single $>$. Acesso em 15 jan. 2020.

[8] Dagienè, Valentina et al. 2006. Information technology contests--introduction to computer science in an attractive way. Informatics in Education-An International Journal, v. 5, n. 1, p. 37-46.

[9] DK publishing. The Incredible Math Games Book. 2015.

[10] Dresch, A. et al. Design Science Research: Método de pesquisa para avanço da Ciência e Tecnologia. Porto Alegre: Bookman, 2015.

[11] Fadjo, C. L.. Developing computational thinking through grounded embodied cognition. 2012. Tese de Doutorado. Columbia University.

[12] Feaster, Yvon et al. 2011. Teaching CS unplugged in the high school (with limited success). In: Proceedings of the 16th ITiCSE. . p. 248-252.

[13] França, R. S. Uma abordagem pedagógica incorporada para o desenvolvimento do pensamento computacional no ensino fundamental. 2020. Tese (Doutorado em Ciência da Computação) - Universidade Federal de Pernambuco, Ciência da Computação, $\quad$ Recife, $2020 . . \quad$ Disponível em $<$ https://repositorio.ufpe.br/handle/123456789/38542>. Acesso em 26 de jan. 2021.

[14] França, R. S.; Tedesco, P. Sertão.Bit: Um livro-jogo de difusão do pensamento computacional. In: V Workshop de Ensino em Pensamento Computacional, Algoritmos e Programação, 2019, Brasília. Anais dos Workshops do VIII Congresso Brasileiro de Informática na Educação, 2019.

[15] Gardeli, Anna; vosinakis, Spyros. 2018. The Effect of Tangible Augmented Reality Inter-faces on Teaching Computational Thinking: A Preliminary Study. In: ICL Conference. Springer, Cham, p. 673-684.

[16] Hayashi, Elaine CS et al. 2016. Exploring new formats of the Self-Assessment Manikin in the design with children. In: Proceedings of the 15th Brazilian Symposium on Human Factors in Computing Systems. p. 1-10.

[17] Hsu, Ting-Chia et al.. 2018. How to learn and how to teach computational thinking: Suggestions based on a review of the literature. Computers \& Education, v. 126, p. 296-310.

[18] Jenkins, H. Transmedia Storytelling 101. 2007. Disponível em $<$ http://henryjenkins.org/blog/2007/03/transmedia_storytelling_101.html $>$. Acesso em: 27 jan. 2020.

[19] Johnson-Glenberg, Mina C. et al .2016. Effects of embodied learning and digital platform on the retention of physics content: Centripetal force. Frontiers in psychology, v. 7, p. 1819.

[20] Kafai, Yasmin et al. 2019. From Theory Bias to Theory Dialogue: Embracing Cognitive, Situated, and Critical Framings of Computational Thinking in K-12 CS Education. In: Proceedings of the 2019 ACM ACE. p. 101-109.

[21] Kubica, Jeremy. Computational fairy tales. Jeremy Kubica, 2012.

[22] Lee, Irene et al. 2011. Computational thinking for youth in practice. Acm Inroads, v. 2, n. 1, p. 32-37.

[23] Liukas, Linda. Hello Ruby: adventures in coding. Macmillan, 2015.

[24] Marcu, Gabriela et al. 2010. Design and evaluation of a computer science and engineering course for middle school girls. In: Proceedings of the 41st SIGCSE. p. 234-238.

[25] Moraes, Roque. Análise de conteúdo. Revista Educação, Porto Alegre, v. 22, n. 37, p. 7-32, 1999.

[26] Ortiz et al. 2018. Aspectos do Contexto Sociocultural dos Alunos estão Presentes nas Pesquisas para Ensinar Pensamento Computacional?. In: Anais dos Workshops do VII CBIE. p. 520-529.

[27] Papert, S.. Mindstorms; Children, Computers and Powerful Ideas. New York: Basic Book, 1980

[28] Parham-mocello, Jennifer et al. 2019. Story Programming: Explaining Computer Science Before Coding. In: Proceedings of the 50th SIGCSE. p. 379-385.

[29] Prottsman, Kiki. My First Coding Book. DK. 2017.

[30] Rodrigues, S. et al. 2018. Computação desplugada no ensino de programação: Uma revisão sistemática da literatura. In: XXIX SBIE. p. 417.
EduComp’21, Abril 27-30, 2021, Jataí, Goiás, Brasil (On-line)

[31] Rodriguez, Brandon et al. 2017. Assessing computational thinking in CS unplugged activities. In: Proceedings of the 2017 ACM SIGCSE. p. 501-506

[32] Román González, Marcos. Codigoalfabetización y pensamiento computacional en Educación Primaria y Secundaria: validación de un instrumento y evaluación de programas . 2016. Universidad Nacional de Educación a Distancia (España). Escuela Internacional de Doctorado. Programa de Doctorado en Educación.

[33] Rother, E. T.. Revisão sistemática X revisão narrativa. Acta paulista de enfermagem, v. 20, n. 2, p. v-vi, 2007.

[34] SBC - Sociedade Brasileira de Computação. Diretrizes para ensino de Computação na Educação Básica. 2019. Disponível em $<\mathrm{https}$ ///www.sbc.org.br/documentos-da-sbc/send/203-educacao-basica/1220bncc-em-itinerario-informativo-computacao-2 >. Acesso em: 23 jan. 2020.

[35] Selby, C., Woollard, J. 2013. Computational thinking: the developing definition. Disponível em <https://eprints.soton.ac.uk/356481/>. Acesso em 15 jan. 2020.

[36] Shadish , W. R.; Cook, T. D.; Campbell, D. T. Experimental an quasiexperimental designs for generalized causal inference. Boston: Houghton Mifflin Company, 2002.

[37] Shapiro, Samuel S.; Francia, R. S. 1972. An approximate analysis of variance test for normality. Journal of the American Statistical Association, v. 67, n. 337, p. 215-216.

[38] Taub, R., Armoni, M., and Ben-Ari, M. 2012. CS unplugged and middle-school students' views, attitudes, and intentions regarding CS. ACM Trans. Comput. Educ. 12, 2, Article 8 (April 2012), 29pages.

[39] Tsarava, Katerina et al. 2019. Cognitive Correlates of Computational Thinking: Evaluation of a Blended Unplugged/Plugged-In Course. In: Proceedings of the 14th WiPSCE. p. 1-9.

[40] Usborne Publishing. Brincar e aprender: Computadores e programação. 2015.

[41] Valente, José Armando. 2016. Integração do pensamento computacional no currículo da educação básica: diferentes estratégias usadas e questões de formação de professores e avaliação do aluno. Revista E-curriculum, v. 14, n. 3, p. 864-897.

[42] Van Solingen, r.; Berghout, e.. The Goal/Question/Metric Method: a practical guide for quality improvement of software development. London: McGraw- Hill, 1999.

[43] Vicari, R. M et al. Pensamento computacional: revisão bibliográfica. 2018. Disponível em $<$ https://lume.ufrgs.br/handle/10183/197566>. Acesso em: 23 jan. 2020.

[44] Vygotzky, L.S. (1978) Mind in Society. New York: Cambridge University Press.

[45] Wing, Jeannette M. Computational thinking. Communications of the ACM, v. 49, n. 3, p. 33-35, 2006.

[46] Yu, Junnan; Roque, Ricarose. A review of computational toys and kits for young children. International Journal of Child-Computer Interaction, 2019. 